\title{
One-step synthesis of Pt/a-CoO core/shell nanocomposites
}

\author{
Daewoon Kim, Sung Joo Kim and Jong Min Yuk (D)
}

\begin{abstract}
Herein, we synthesize a core/shell Pt/a- $\mathrm{CoO}_{x}$ nanocomposite via one-step synthesis using a strong reaction agent of borane t-butylamine(BBA) at $200^{\circ} \mathrm{C}$. Transmission electron microscopy study shows that the morphology of nanocomposites is controlled by the stirring time and perfect core/shell structure is formed with over 7 days stirring time.
\end{abstract}

Keywords: One-step synthesis, Nanocomposites, TEM, EDS

\section{Introduction}

Nanocomposites containing Pt have attracted great attentions due to their excellent catalytic, electric and magnetic properties. (Peng and Yang, 2009; Li et al. 2015; Zhang et al. 2013; Wang et al. 2015; Esfahani et al. 2010; Wang et al. 2010) Since these properties closely intertwine with their size, shape and composition, designing nanocomposites is critical to their chemical, electrical and energy applications. (Pushkarev et al. 2012; Vidal-lglesias et al. 2012; Mostafa et al. 2010; Wang et al. 2013) Among diverse nanocomposites, core/shell structures of $\mathrm{Pt} /$ transition metal oxide, such as $\mathrm{Pt} / \mathrm{Fe}_{2} \mathrm{O}_{3}, \mathrm{FePt} / \mathrm{Fe}_{3} \mathrm{O}_{4}$ or $\mathrm{Pt} /$ $\mathrm{CoO}$, not only show remarkable magnetic properties, but also contain small amount of expensive Pt. (Alayoglu et al. 2008; Tao et al. 2008; Zhao and Xu, 2006; Zhou et al. 2005; Teng et al. 2003; Zeng et al. 2004; Yin et al. 2004; Habas et al. 2007) Traditionally, the core/shell structures have been synthesized by a two-step growth method. (Tao et al. 2008; Liu et al. 2005; Yu et al. 2014) Core nanoparticles are synthesized first as seeds, followed by growth of the shell around the core. However, the two-step growth technique typically suffers from low yield because the synthesized core particles are not well dispersed and shell materials independently coalesce each other instead of adhering to the core. In our study, we report a (scanning) transmission electron microscopy ((S)TEM) study of Pt/ amorphous cobalt oxide $\left(\mathrm{a}-\mathrm{CoO}_{\mathrm{x}}\right)$ nanocomposites growth by one-step heating synthesis.

\footnotetext{
* Correspondence: jongmin.yuk@kaist.ac.kr

Department of Materials Science and Engineering, KAIST, Daejeon 305-701, South Korea
}

(c) The Author(s). 2019 Open Access This article is distributed under the terms of the Creative Commons Attribution 4.0 International License (http://creativecommons.org/licenses/by/4.0/), which permits unrestricted use, distribution, and reproduction in any medium, provided you give appropriate credit to the original author(s) and the source, provide a link to the Creative Commons license, and indicate if changes were made.

\section{Results and discussion}

TEM/STEM images in Fig. 2 show the effect of a BBA additive on a synthesis of $\mathrm{Pt} / \mathrm{CoO}_{x}$ nanocomposites. Without BBA addition into the precursor solution, the synthesized Pt and Co are formed separately with forming a compound. (Fig. 2)a Using the Z(atomic number)-contrast dark-field STEM imaging, $5 \mathrm{~nm}$ sized bright nanoparticles 


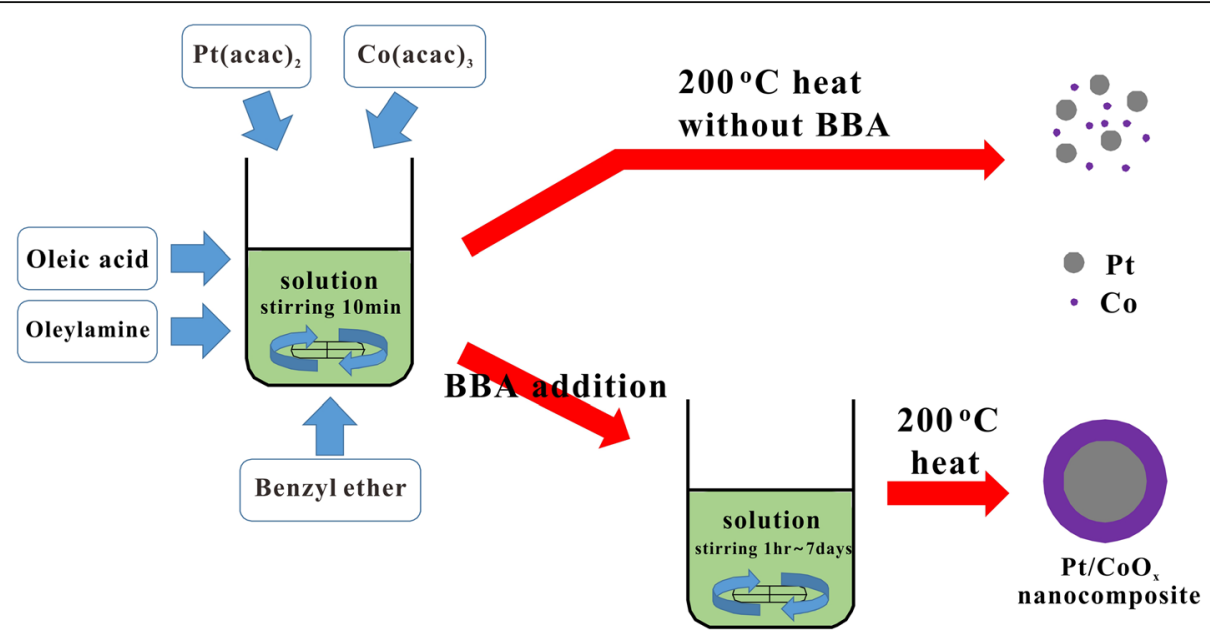

Fig. 1 Schematic illustration of the synthesis procedure for $\mathrm{Pt} / \mathrm{CoO}_{x}$ nanocomposite

are likely Pt while the rests with a size distribution of 0.96 $\pm 0.56 \mathrm{~nm}$ are Co. (Fig. 2b, Additional file 1: Figure S1) In the synthesis, the color of the reaction solution changes from yellow to black at around $140{ }^{\circ} \mathrm{C}$ when $\mathrm{Pt}(\mathrm{acac})_{2}$ only added in the solution. On the other hand, the color of the solution does not change at around $200{ }^{\circ} \mathrm{C}$ for $2 \mathrm{~h}$ when $\mathrm{Co}(\mathrm{acac})_{3}$ only added. However, in our study, the reduction reaction of $\mathrm{Co}(\mathrm{acac})_{3}$ is observed at $200{ }^{\circ} \mathrm{C}$ when two precursors are simultaneously added. This shows that pre-synthesized Pt nanoparticles act as catalysts to lower the reduction temperature of $\mathrm{Co}(\mathrm{acac})_{3}$ to below $200{ }^{\circ} \mathrm{C}$. However, the number of formed Pt nanoparticles is not sufficient enough for Co reduction to grow Co nanoparticles, making $\mathrm{Pt}$ and Co form separately.
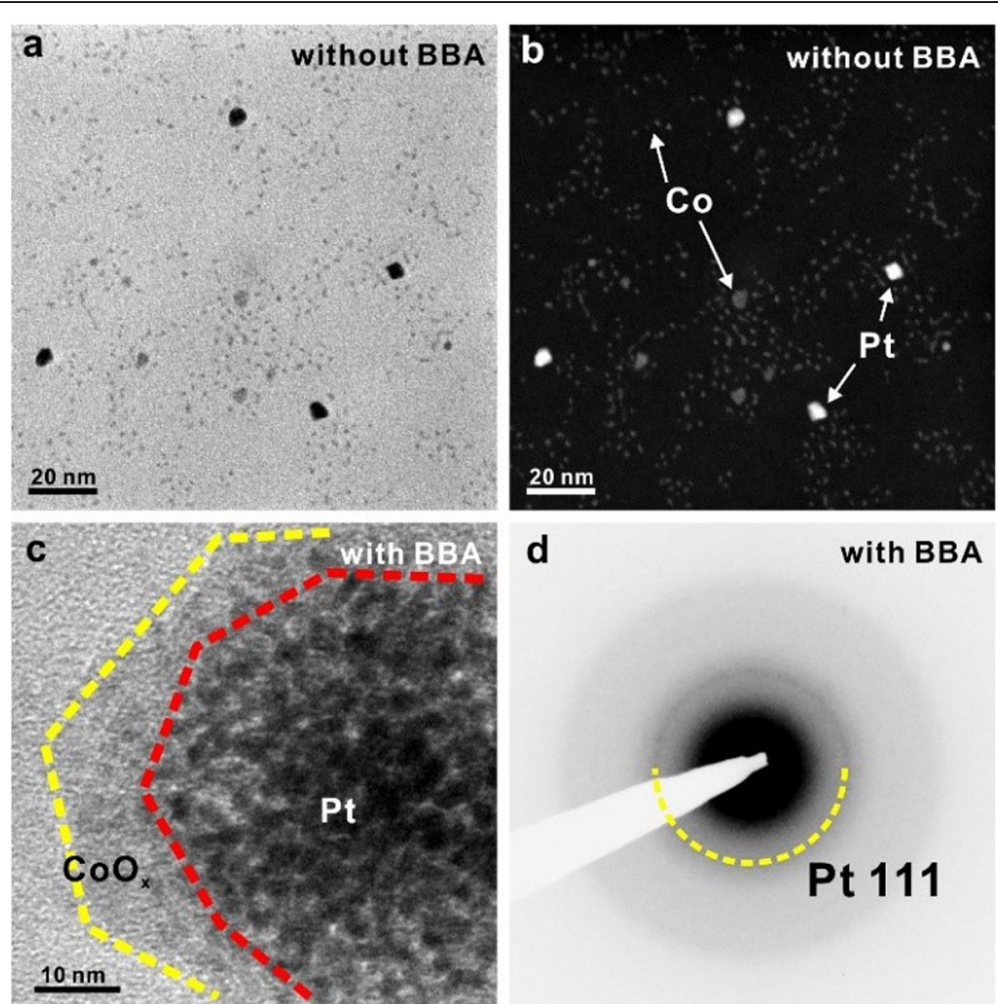

with BBA

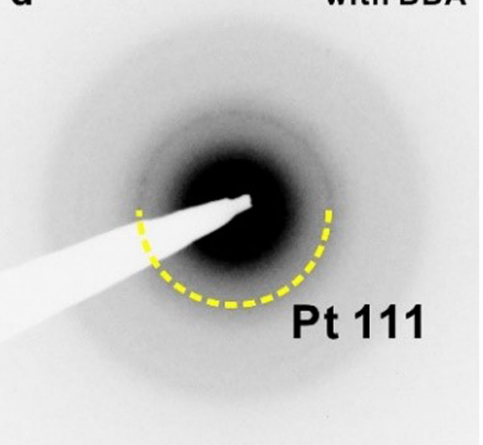

Fig. 2 TEM image of Pt/CoOx nanocomposite (a) Bright-field and (b) dark-field STEM images of Pt and Co nanoparticles without using a BBA additive during synthesis. c TEM image of synthesized $\mathrm{Pt} / \mathrm{a}-\mathrm{CoO}_{\mathrm{x}}$ core/shell nanocomposites when using a BBA additive. $\mathbf{d}$ Selected area electron diffraction (SAED) pattern of area (c) 
Thus, we recognize that Pt nanoparticles need to be reduced at much lower than $140{ }^{\circ} \mathrm{C}$ in order to produce a composite of $\mathrm{Pt}$ and Co. Figure $2 \mathrm{c}$ shows the bright field TEM image of $\mathrm{Pt} / \mathrm{CoO}_{\mathrm{x}}$ nanocomposites with the addition of BBA. By adding BBA inside the solution, the color of the solution changes to black at $60{ }^{\circ} \mathrm{C}$. This shows that reduction temperature of $\mathrm{Pt}(\mathrm{acac})_{2}$ is lowered below $60{ }^{\circ} \mathrm{C}$. This change makes Pt nanoparticles form inside the solution much more than the one without BBA to ultimately have the reduced cobalt clusters increased. With BBA, the synthesized nanostructure forms a core-shell structure. Pt nanoparticles are well distributed with amorphous shells wrapped around them. In a selected area electron diffraction (SAED) pattern of the nanocomposite, polycrystalline Pt is formed in a core with an amorphous shell formed outside. (Fig. 2d).

In order to change the morphology of nanocomposites, we further modify the synthesis of $\mathrm{Pt} / \mathrm{CoO}_{\mathrm{x}}$ nanocomposites by adjusting the stirring time at $50{ }^{\circ} \mathrm{C}$ (Fig. 3). Under $1 \mathrm{~h}$ stirring, Pt nanoparticles are found to spread widely while the shell structure is grown to surround them (Fig. 3a). Under 1 day stirring, Pt nanoparticles coalesce to form a larger nanocomposite core than that with $1 \mathrm{~h}$ stirring (Fig. 3b). Finally, under 7 days stirring, Pt nanoparticles are aggregated to a size in between
50 and $100 \mathrm{~nm}$, while an amorphous shell surrounds uniformly to form a perfect spherical shape (Fig. 3c). The overall size of core/shell nanocomposites is $100 \sim 200 \mathrm{~nm}$.

Although BBA originally reduces Pt precursors at 60 ${ }^{\circ} \mathrm{C}$, stirring at $50{ }^{\circ} \mathrm{C}$ for a sufficiently long time after adding BBA produces agglomerated Pt seeds without growth due to low temperature. When the temperature is raised, the seeds grow and accumulate in the core. Further increasing the temperature reduces the Co precursor to form an oxide shell around the core. Figure $3 \mathrm{~d}$ shows the high-resolution TEM image of the outer surface of the synthesized core/shell nanocomposites. It is clear that the shell is composed of an amorphous structure but with $3 \mathrm{~nm}$ crystalline $\mathrm{CoO}_{x}$ formed on the outermost surface. A corresponding fast Fourier transform (FFT) image identifies the structure to be $\mathrm{Co}_{3} \mathrm{O}_{4}$. This suggests that the surface of the nanocomposites transforms from amorphous to crystalline by exposing it to air.

Figure 4 shows the STEM EDS mapping for composition analysis of core/shell nanocomposites. At the nanocomposite core, it is confirmed that the bright area in a STEM image in Fig. 4a consists of Pt while (Fig. 4b) Co and $\mathrm{O}$ are shown at the shell (Fig. 4c, d). The quantitative analysis clearly suggests that the shell structure is $\mathrm{Co}_{3} \mathrm{O}_{4-\mathrm{x}}$ (Additional file 1: Figure S2). In Fig. 4b, the

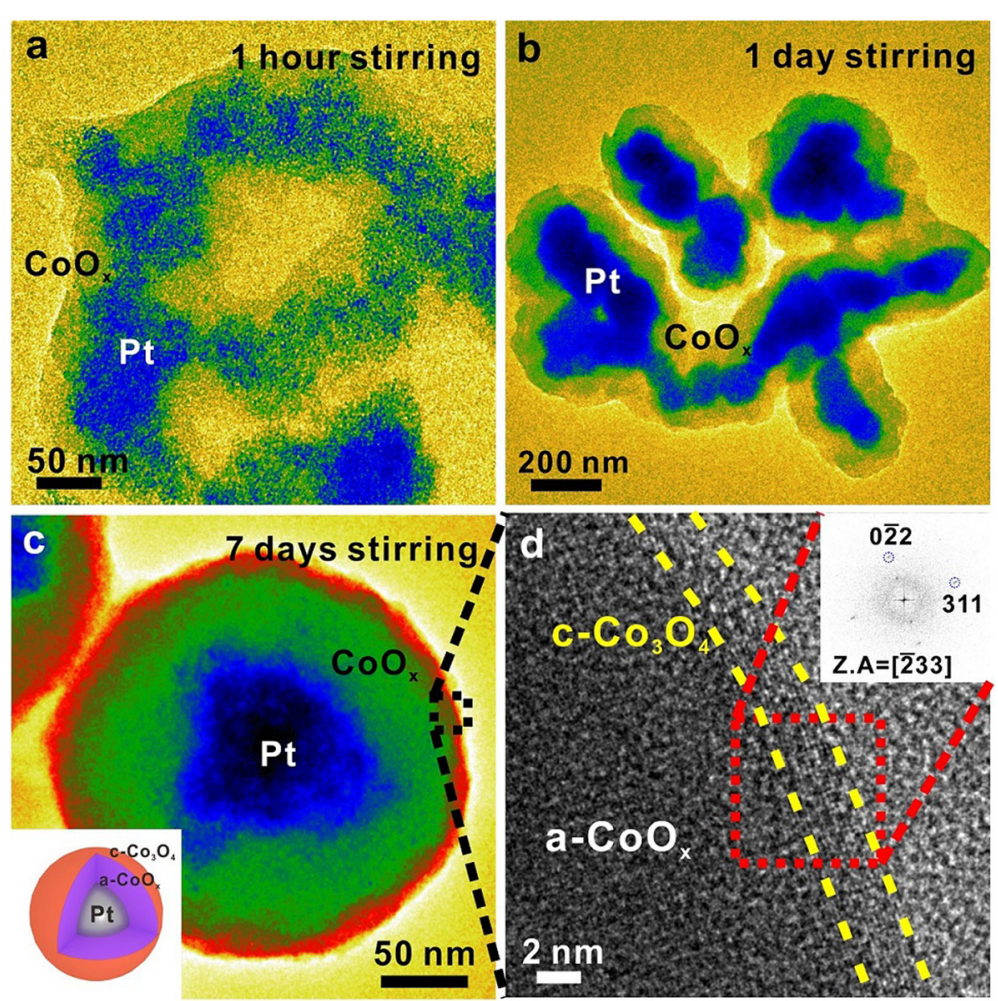

Fig. 3 Bright-field TEM images and high-resolution TEM analysis of the one-step synthesized $\mathrm{Pt} / \mathrm{CoO}_{x}$ nanocomposites under various stirring conditions (a) $1 \mathrm{~h}$, (b) 1 day and (c) 7 days. Inset: Schematic illustration of the synthesized Pt/CoO core/shell nanocomposite. $\mathbf{d}$ Zoomed in highresolution image of a square box in (c). Inset: fast Fourier transform (FFT) pattern of a red square in (d) 

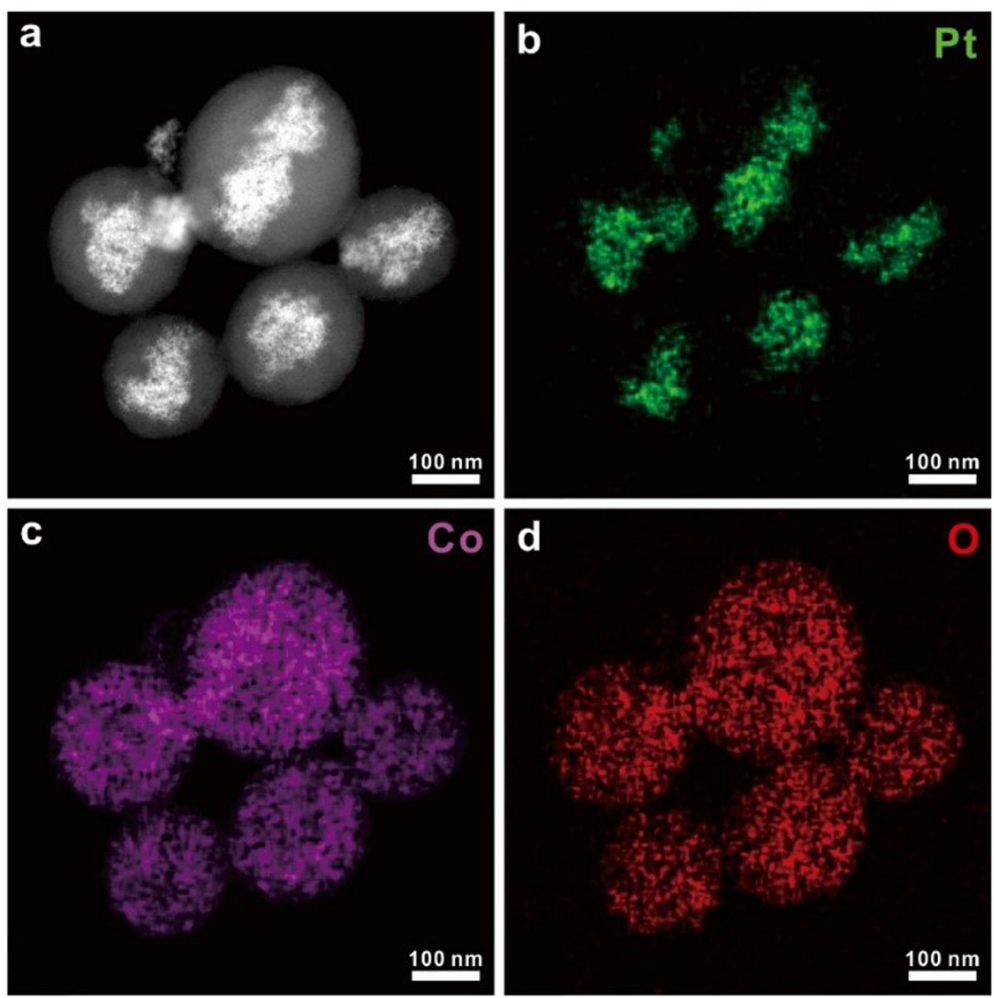

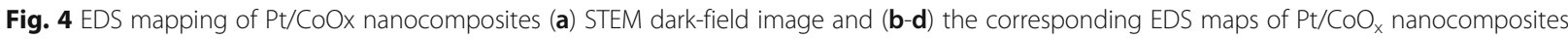
after 7 days of stirring

morphology of Pt is distributed like a band in a specific direction. However, in Fig. 4c and Fig. 4d, Co and O have a spherical shape. This result shows that the magnetic stirring caused the aggregation of $\mathrm{Pt}$ seeds to be banded in a specific direction, and then the $\mathrm{CoO}_{\mathrm{x}}$ shell was formed after temperature rises.

\section{Conclusion}

We synthesize the $\mathrm{Pt} / \mathrm{a}-\mathrm{CoO}_{\mathrm{x}}$ core/shell nanocomposites using one-step method. BBA is added to allow reduction of Pt and Co precursors to occur at low temperature. Low temperature stirring is performed to change the morphology of nanocomposites. After 7 days stirring, the core/shell nanocomposites are synthesized in which $\mathrm{Pt}$ nanoparticles are formed in the core with amorphous/ crystalline cobalt oxide formed at the shells.

\section{Supplementary information}

Supplementary information accompanies this paper at https://doi.org/10. 1186/s42649-019-0016-2.

Additional file 1: Figure S1. Size distribution of cobalt nanoparticles in Fig. 2b. average size of cobalt nanoparticles is $0.96 \mathrm{~nm}$, and standard deviation of the sizes is $0.56 \mathrm{~nm}$. Figure $\mathbf{S 2}$. Quantitative EDS graph of the entire particle in Fig. 4. Atomic ratio of cobalt and oxygen is 45:55, seems very close to $\mathrm{CO}_{3} \mathrm{O}_{4}$.

\section{Abbreviations}

(S)TEM: (scanning) transmission electron microscopy; acac: acetylacetonate; BBA: Borane t-butylamine; BF: Bright-field; DF: Dark-field; EDS: Energydispersive X-ray spectroscopy; FFT: Fast fourier transform; SAED: Selected area diffraction pattern

\section{Acknowledgements}

No applicable.

\section{Authors' contributions}

DK has contributed to sample preparation, data analysis, and original data writing. SJK has contributed to TEM imaging. JMY has contributed for review and editing the manuscript. All authors read and approved the final manuscript.

\section{Funding}

This work supported by NRF grant funded by the Korea government (MSIP; Ministry of Science, ICT \& Future Planning) (NRF2018R1C1B6002624) and Nano-Material Technology Development Program through the NRF funded by the Ministry of Science, ICT and Future Planning (2009-0082580).

\section{Availability of data and materials}

The datasets used and/or analyzed during the current study are available from the corresponding author on reasonable request. 
Received: 29 August 2019 Accepted: 25 October 2019

Published online: 14 November 2019

\section{References}

S. Alayoglu, A.U. Nilekar, M. Mavrikakis, B. Eichhorn, Ru-Pt core-shell nanoparticles for preferential oxidation of carbon monoxide in hydrogen. Nat. Mater. 7, 333 (2008)

H.A. Esfahani, L. Wang, Y. Nemoto, Y. Yamauchi, Synthesis of bimetallic Au@Pt nanoparticles with $\mathrm{Au}$ core and nanostructured Pt shell toward highly active electrocatalysts. Chem. Mater 22, 6310 (2010)

S.E. Habas, H. Lee, V. Radmilovic, G.A. Somorjai, P. Yang, Shaping binary metal nanocrystals through epitaxial seeded growth. Nat. Mater. 6, 692 (2007)

Q. Li, L. Wu, G. Wu, D. Su, H. Lv, S. Zhang, W. Zhu, A. Casimir, H. Zhu, A.M. Garcia, S. Sun, New approach to fully ordered fct-FePt nanoparticles for much enhanced electrocatalysis in acid. Nano Lett 15, 2468 (2015)

C. Liu, X. Wu, T. Klemmer, N. Shukla, D. Weller, Reduction of sintering during annealing of FePt nanoparticles coated with iron oxide. Chem. Mater. $17,620(2005)$

S. Mostafa, F. Behafarid, J.R. Croy, L.K. Ono, L. Li, J.C. Yang, A.I. Frenkel, B.R. Cuenya, Shape-dependent catalytic properties of Pt nanoparticles. J. Am. Chem. Soc. $132,15714(2010)$

Z. Peng, H. Yang, Desinger platinum nanoparticles: Control of shape, composition in alloy, nanostructure and electrocatalytic property. Nano Today 4, 143 (2009)

V.V. Pushkarev, N. Musselwhite, K. An, S. Alayoglu, G.A. Somorjai, High structure sensitivity of vapor-phase furfural decarbonylation/hydrogenation reaction network as a function of size and shape of Pt nanoparticles. Nano Lett. 12, 5196 (2012)

F. Tao, M.E. Grass, Y. Zhang, D.R. Butcher, J.R. Renzas, Z. Liu, J.Y. Chung, B.S. Mun, M. Salmeron, G.A. Somorjai, Reaction-driven restructuring of Rh-Pd and Pt-Pd core-shell nanoparticles. Science 322, 932 (2008)

X.W. Teng, D. Black, N.J. Watkins, Y.L. Gao, H. Yang, Platinum-maghemite coreshell nanoparticles using a sequential synthesis. Nano Lett. 3, 261 (2003)

F.J. Vidal-Iglesias, R.M. Aran-Ais, J.S. Gullon, E. Herrero, J.M. Feliu, Electrochemical characterization of shape-controlled Pt nanoparticles in different supporting electrolytes. ACS Catal 2, 901 (2012)

D. Wang, H.L. Xin, R. Hovden, H. Wang, Y. Yu, D.A. Muller, F.J. DiSalvo, H.D. Abruna, Structurally ordered intermetallic platinum-cobalt core-shell nanoparticles with enhanced activity and stability as oxygen reduction electrocatalysts. Nat. Mater. 12, 81 (2013)

D. Wang, Y. Yu, J. Zhu, S. Liu, D.A. Muller, H.D. Abruna, Morphology and activity tuning of Cu3Pt/C ordered intermetallic nanoparticles by selective electrochemical dealloying. Nano Lett. 15, 1343 (2015)

G. Wang, H. Wu, D. Wexler, H. Liu, O. Savadogo, Ni@Pt core-shell nanoparticles with enhanced catalytic activity for oxygen reduction reaction. J. Alloy. Compd. 503, L1 (2010)

Y. Yin, R.M. Rioux, C.K. Erdonmez, S. Hughes, G.A. Somorjai, A.P. Alivisatos, Formation of hollow nanocrystals through the nanoscale kirkendall effect Science 304, 711 (2004)

Y. Yu, W. Yang, X. Sun, W. Zhu, X.Z. Li, D.J. Sellmyer, S. Sun, Monodisperse MPt (M $=\mathrm{Fe}, \mathrm{Co}, \mathrm{Ni}, \mathrm{Cu}, \mathrm{Zn})$ nanoparticles prepared from a facile oleylamine reduction of metal salts. Nano Lett 14, 2778 (2014)

H. Zeng, J. Li, Z.L. Wnag, J.P. Liu, S. Sun, Bimagnetic core/shell FePt/Fe3O4 nanoparticles. Nano Lett. 4, 187 (2004)

L. Zhang, R. Iyyamperumal, D.F. Yancey, R.M. Crooks, G. Henkelman, Design of Ptshell nanoparticles with alloy cores for the oxygen reduction reaction. ACS Nano 7, 9168 (2013)

D. Zhao, B.Q. Xu, Enhancement of Pt utilization in electrocatalysts by using gold nanoparticles. Angew. Chem. Int. Ed. 45, 4955 (2006)

S.H. Zhou, B. Varughese, B. Eichhorn, G. Jackson, K. Mcllwrath, Pt-Cu core-shell and alloy nanoparticles for heterogeneous $\mathrm{NO}(\mathrm{x})$ reduction: anomalous stability and reactivity of a core-shell nanostructure. Angew. Chem. Int. Ed. $44,4539(2005)$

\section{Publisher's Note}

Springer Nature remains neutral with regard to jurisdictional claims in published maps and institutional affiliations.

\section{Submit your manuscript to a SpringerOpen ${ }^{\circ}$ journal and benefit from:}

- Convenient online submission

- Rigorous peer review

- Open access: articles freely available online

- High visibility within the field

- Retaining the copyright to your article

Submit your next manuscript at $\boldsymbol{\nabla}$ springeropen.com 